\title{
A PRODUÇÃO DE ESPÉCIES NATIVAS EM MARABÁ: A LOGÍSTICA DE PRODUÇÃO DE MUDAS NA SEAGRI- MARABÁ
}

\section{THE PRODUCTION OF NATIVE SPECIES IN MARABÁ: THE LOGISTICS OF PRODUCTION OF SEEDLINGS IN SEAGRI-MARABÁ}

\author{
Gabriele Melo de Andrade1; Thayrine Silva Matos²;Jean Carlos Altoé Cunha3; Maria Rita \\ Calandrini de Azevedo ${ }^{4}$; Seidel Ferreira dos Santos ${ }^{5}$
}

DOI: https://doi.org/10.31692/978-65-991061-7-0.397-401

\section{INTRODUÇÃ̃O}

Amazônia é considerada a maior floresta tropical do mundo com uma abundante e ainda desconhecida diversidade de espécies vegetais (MARQUES; SILVA, 2012). Levantamentos realizados por Cardoso et al. (2017) registraram para a bacia amazônica a existência de 14.003 espécies de plantas espermatófitas, distribuídas em 1.788 gêneros e 188 famílias botânicas, desse total $48 \%$ são de árvores que atingem DAP $\geq 10 \mathrm{~cm}$.

Em contrapartida, a vasta biodiversidade vem acompanhada de um alto índice de degradação da região, em julho de 2018 cerca de 360 quilômetros quadrados de floresta foram desmatados na Amazônia legal e o Pará é o estado que apresenta o maior número de áreas abertas, sendo responsável por 95\% das áreas antropizadas (FONSECA et al., 2018).

$\mathrm{Na}$ região amazônica algumas tecnologias são propostas para reduzir o número de áreas alteradas e atender as exigências do código florestal. Dentre estas destacamos os sistemas agroflorestais (SAFs) que são sistemas produtivos que utilizam espécies agrícolas e componentes arbóreos em consórcio com o objetivo de trazer a restauração produtiva de áreas degradadas (SILVA et al, 2010). Um dos pontos mais críticos para implantação de SAFs e dos programas de restauração ambiental e florestal é fornecimento de mudas de espécies nativas, sobretudo, espécies arbóreas. Neste sentido a presença de viveiros em regiões estratégicas como o sudeste do Pará é de extrema importância para alimentar a cadeia produtiva de produção de nativas para fins de restauração florestal. A produção de mudas em viveiros florestais consiste a etapa mais importante para o sucesso dos programas de restauração e fomento da agricultura familiar no sudeste do Pará, principalmente na cidade de Marabá e regiões próximas.

Além disso, o viveiro de mudas como cadeia produtiva para sistemas agroflorestais

\footnotetext{
${ }^{1}$ Graduando em Engenharia Florestal, Universidade do Estado do Pará, andradegm@outlook.com

${ }^{2}$ Graduando em Engenharia Florestal, Universidade do Estado do Pará, thayrine.matos@gmail.com

${ }^{3}$ Graduando em Engenharia Florestal, Universidade do Estado do Pará, Jealtoe@ hotmail.com

${ }^{4}$ Graduando em Engenharia Florestal, Universidade do Estado do Pará, mritacalandrini@gmail.com

${ }^{5}$ Doutor em Biodiversidade e Tecnologia, Universidade do Estado do Pará, botanish@ yahoo.com
} 
contribui significativamente para economia da região em que se localiza. Visto que, esse espaço produtivo permite que a unidade de produção familiar garanta a segurança alimentar da família, além de ser uma alternativa econômica viável para os agricultores familiares (PEREIRA et al, 2010).

A cidade de Marabá, localizada no Sudeste do Pará possui uma grande demanda por mudas, pois apresenta uma vasta quantidade de produtores rurais em seus arredores. Esta demanda exige um viveiro que consiga atender a todos com eficiência e com mudas de qualidade. Em vista disso, essa pesquisa tem como objetivo caracterizar um viveiro localizado na cidade de Marabá-PA, a fim de compreender a sua dinâmica econômico-produtiva e sistematizar informações uteis na busca por mudas de qualidade e em quantidade satisfatória aos interessados, além de averiguar as técnicas utilizadas na produção.

\section{FUNDAMENTAÇÃO TEÓRICA}

A exploração desordenada de espécies nativas da Amazônia causa perdas valiosas de espécies que tinham potencial silvicultural ainda desconhecido. Diante disso, a preocupação mundial tem sido cada vez maior em relação a qualidade desse ambiente, por isso desenvolver a produção de mudas de forma adequada possibilita a recomposição do ecossistema e a renovação de sua qualidade, proporcionando a volta dessas espécies para o seu ambiente de origem (SILVA et al., 2007).

A regeneração natural das espécies nativas perdidas para a exploração de madeira na Amazônia tem sido pouco estudada. O plantio de espécies nativas demanda de um cuidado minucioso que necessita de estudos sobre o ciclo de vida destas espécies para que sejam reproduzidas e assim possam retornar à floresta (PINTO et al., 1993).

O aumento de projetos de reflorestamento e de sistemas agroflorestais (SAF's) a fim de cumprir obrigatoriedades legais e para futura exploração de madeira de forma sustentável gerou uma maior demanda de muda de espécies florestais nos últimos anos (MAGALHÃES, 1982). Em vista disso, a presença de um viveiro em regiões que demandam grande quantidade de mudas de espécies nativas de qualidade possibilita um maior desenvolvimento do setor florestal e ainda contribui significativamente para a recomposição de áreas degradadas da região.

\section{METODOLOGIA}

O viveiro selecionado para a realização do trabalho localiza-se na região metropolitana de Marabá - PA, Agrópolis do INCRA, nas instalações da Secretaria de Agricultura 
(SEAGRI) do município (5²1’66’’S 4907’55” O).

Foi realizada uma pesquisa de campo para observação das atividades e coleta de informações referentes aos aspectos do trabalho e produção de mudas. Para a aquisição de informações fez-se uso de um questionário semiestruturado com 15 perguntas abertas abrangendo termos técnicos de produção, aspectos sociais e econômicos envolventes. Para a construção do questionário foram realizadas pesquisas técnicas e socioeconômicas com a finalidade de melhor entendimento da dinâmica do estabelecimento e interação com as características e funcionamento do viveiro.

De posse do questionário respondido, com informações suficientes para uma análise do sistema de produção de mudas da região foi construído um diagnóstico, que relaciona aspectos técnicos, produtivos, sociais e ambientais.

\section{RESULTADOS E DISCUSSÕES}

A microrregião de Marabá possui atualmente apenas uma unidade para produção de mudas florestais. Tendo uma área total de aproximadamente 2,8 hectares, o viveiro tem sua produção de mudas bastante variada para diversos fins. Foi criado em 2015 com a capacidade de produção para 1.000.000 (um milhão) de mudas, sendo 800.00 em tubetes e 200.000 em saquinhos, entretanto atualmente a produção anual é de aproximadamente 600.000 mudas, entre saquinhos e tubetes.

A partir do questionário aplicado, observou-se a preferência pela produção de algumas espécies frutíferas e florestais, justificando-se pela maior procura das mesmas por agricultores. A Tabela 1 demonstra as espécies que demandam maior produção.

Tabela 1. Lista de espécies produzidas no viveiro da SEAGRI

\begin{tabular}{cccc}
\hline Nome popular & Nome cientifico & Família & Utilização \\
\hline Açai & Euterpe oleracea Mart. & Arecaceae & Frutífera \\
Cupu-açu & $\begin{array}{c}\text { Theobroma grandiflorum } \text { (Willd. } \\
\text { ex Spreng.) K. Schum. }\end{array}$ & Malvaceae & Frutífera \\
Cacau & Theobroma cacao L. & Malvaceae & Frutífera \\
Mogno & Swietenia macrophylla King & Meliaceae & Florestal \\
Jatobá & Hymenaea courbaril L. & Fabaceae & Florestal \\
Ipê & Tabebuia sp. & Bignoniaceae & Florestal \\
Pau preto & Cenostigma tocantinum Ducke & Fabaceae & Florestal \\
Nim & Azadirachta indica A. Juss & Meliaceae & Florestal \\
\hline
\end{tabular}


As sementes possuem diversos fornecedores, mas provém principalmente da agricultura familiar que também faz uso das mudas do viveiro, além de instituições parceiras da SEAGRI, bem como IDERFLORBio, Secretaria de Estado de Desenvolvimento Agropecuário e da Pesca - SEDAP e cooperativas de extrativismos da região.

As mudas não possuem valores para vendas, ou seja, toda a produção tem apenas o objetivo de doação para agricultura familiar da região de forma individual e coletiva, mas realiza doação também para escolas, universidades, associações e entidades privadas através de parcerias. As mudas são entregues mediante a realização de um cadastro do produtor, com dados a respeito do tamanho da área que serão plantadas as mudas, as espécies de interesse e a existência ou não de um método de irrigação e a formalização de todas as informações através de um termo de compromisso.

As espécies são procuradas para muitas utilizações, mas especificamente para produção vegetal, recuperação de áreas degradadas e nascentes e principalmente para implantação de SAFs. Diante disso a época de maior distribuição de mudas ocorre prioritariamente no período chuvoso (novembro a abril), pois assim há o melhor aproveitamento das condições climáticas, proporcionando o bom desenvolvimento das espécies plantadas.

\section{CONCLUSÕES}

O viveiro da SEAGRI- Marabá tem grande capacidade de produção de mudas e atende a demanda da população da região. A estrutura é de grande porte e possui os equipamentos necessários para desenvolver mudas de qualidade em grande quantidade. O local é mantido através do incentivo do governo e por isso a distribuição de mudas é através da doação aos interessados, que devem apenas fazer um breve cadastro. A maior demanda por mudas parte de agricultores da região que utilizam na recuperação de áreas degradadas, na implantação de SAF's e na produção vegetal. A maioria das espécies cultivadas no viveiro são espécies florestais e espécies frutíferas, consequentemente as que demandam maior produção.

\section{REFERÊNCIAS}

CARDOSO, D.; SARKINEN, T.; ALEXANDER, S.; AMORIM, A.; BITTICH, V.; CELIS, M. DALY, D. C; FUNK, V.; TAYLOR, C. M; TROVO, M.; VIANA, P. L.; ZARTMAN, C. E.; FORZZA, R. C. Amazon plant diversity revealed by a taxonomically veri- fied species list. Proceedings of the National Academy of Sciences of the United States of America, v. 114, n. 40, p. 10695-10700, 2017. 
FONSECA, A., JUSTINO, M., CARDOSO, D., RIBEIRO, J., SALOMÃO, R., SOUZA Jr., C., \& VERÍSSIMO, A. Boletim do desmatamento da Amazônia Legal (dezembro de 2017) SAD (p. 1). Belém: Imazon, 2018.

MAGALHÃES, L. Produção de sementes de essências nativas em floresta primária na Amazônia. Acta Amazonica, v. 12, n. 2, p. 257-262, 1982.

MARQUES, W. F.; SILVA, J. J. M. C. Unidades de Conservação no Bioma Amazônico e a Perícia Ambiental. Pontifícia Universidade Católica de Goiás, p. 20. Goiás, 2012.

PEREIRA, C. N.; MANESCHY, R. Q.; OLIVEIRA, P. D.; OLIVEIRA, I. K. S. Caracterização de quintais agroflorestais no projeto de assentamento belo horizonte I, São Domingos do Araguaia, Pará. Agrossistemas, Belém, v. 2, n. 1, p.73-81, out. 2010.

PINTO, A. M.; VARELA, V. P.; BATALHA, L. FP. Influência do sombreamento no desenvolvimento de mudas de Louro pirarucu (Licaria canella (Meissn.) Kosterm.). Acta amazonica, v. 23, n. 4, p. 397-404, 1993.

SILVA, M. H. V.; MELLO, A. H.; MICHELOTTI, F. Caracterização dos viveiros produtores de mudas de essências florestais de marabá e região. Agrossistemas, Belém, v. 2, n. 1, p.9898, out. 2010 .

SILVA, M. H. V.; MICHELOTTI, F. Análise da produção de mudas por viveiros na região sudeste do pará. Agrossistemas, Belém, v. 1, n. 1, p.6-6, set. 2009.

SILVA, R. D., FREITAS, G. D., SIEBENEICHLER, S. C., MATA, J. D., \& CHAGAS, J. R. Desenvolvimento inicial de plântulas de Theobroma grandiflorum (Willd. ex Spreng.) Schum. sob influência de sombreamento. Acta amazónica, 37(3), 365-370. 2007 